\title{
Vibration Analysis of a 51-Story Tower from the Recorded Data of the Earthquake, Typhoon and Ambient Vibration
}

\author{
Kun-Sung Liu \\ Department of Civil Engineering \& Hazard Mitigation Research Center, Kao Yuan University, Taiwan \\ Email: 1k.sung99@msa.hinet.net
}

How to cite this paper: Liu, K.-S. (2018) Vibration Analysis of a 51-Story Tower from the Recorded Data of the Earthquake, Typhoon and Ambient Vibration. World Journal of Engineering and Technology, 6, 161-175.

https://doi.org/10.4236/wjet.2018.61009

Received: December 6, 2017

Accepted: February 24, 2018

Published: February 27, 2018

Copyright $\odot 2018$ by author and Scientific Research Publishing Inc. This work is licensed under the Creative Commons Attribution International License (CC BY 4.0).

http://creativecommons.org/licenses/by/4.0/

(c) (i) Open Access

\begin{abstract}
This study uses the in-structure recordings to investigate the vibration characteristics of a 51-story steel high-rise building in response to a major earthquake, typhoon and ambient vibrations. This presents an opportunity for us to compare the building behaviors, especially their modal properties under different types of excitation. First, we use a two-stage regression procedure to obtain the relations of the building response, including peak floor acceleration and velocity as a function of the wind speed and floor height of the building. Secondly, the structural dynamic characteristics of the high rise building, including the transfer functions and natural frequencies, excited by the Chi-Chi earthquake, Typhoon Aere, and ambient vibrations are also determined and compared. As a result, from the formulas for building response, the predicted peak floor acceleration is higher in the lateral (EW) component than in the longitudinal (NS) component. This is probably due to the greater stiffness of the building in the longitudinal direction than in the lateral direction. In addition, after having identified the $1^{\text {st }}, 2^{\text {nd }}$, and $3^{\text {rd }}$ natural frequencies using the recorded data from the earthquake, typhoon and ambient vibrations, the ranking of the fundamental natural frequencies from low to high is the Chi-Chi earthquake, Typhoon Aere and the ambient vibrations. This means that greater excitation forces of the earthquake have resulted in lower natural frequencies than that produced by the typhoon and ambient vibrations.
\end{abstract}

\section{Keywords}

Earthquake, Typhoon, Peak Floor Acceleration, Peak Floor Velocity, Vibration Analysis 


\section{Introduction}

Taiwan is located along the circum-Pacific seismic belt. From the historical record, many damaging earthquakes had occurred in Taiwan. Earthquakes have caused great loss of lives in Taiwan. In addition to earthquakes, typhoons are the most catastrophic weather phenomenon in Taiwan. The country has experienced 198 typhoons (tropical cyclones) in the past 43 years, averaging more than four typhoons per year [1]. Major typhoons can produce strong winds and heavy rainfalls, causing severe damages to agriculture, housing, and industry, as well as serious loss of human life. Thus, the safety of building structures and their contents, as well as the comfort of occupants under such strong external forces of earthquakes and typhoons remains a major engineering concern.

The full-scale measurements of tall buildings during severe storms and earthquakes are still insufficient although many tall buildings have been built around the world [2]. Field measurements can provide the most realistic data evaluating wind and earthquake effects on and dynamic properties of buildings and structures. Monitoring of wind and earthquake effects on tall buildings can provide important validation of design procedures and assurance of acceptable behavior [3]-[9]. Preciously, we obtained these digital recordings of earthquake and typhoon from the Taiwan Strong Motion Instrumentation Program (TSMIP) network operated by the CWB of Taiwan to analyze the vibration characteristics of a 51-story Tower. The TSMIP network has been designed to enhance the ability to monitor strong earthquakes and to collect high-quality instrumental recordings of building array and free-field ground shaking [10].

In addition, Typhoon Aere passed by northern Taiwan on 24 August 2004. The measured wind data at the Taipei meteorological station and the structural array data recorded in the 51-story SK Tower in Taipei are analyzed in this paper to obtain the relations of the building response, in terms of the peak floor acceleration and velocity as a function of wind speed and story height. Furthermore, the structural dynamic characteristics of this tall building, including the transfer functions and natural frequencies of vibration, excited by the typhoon and the M7.6 Chi-Chi earthquake as well as ambient vibrations, are also determined and compared.

\section{Data Used}

\subsection{Measurement Instrumentation}

Not only to analyze the vibration characteristics of earthquake, typhoon and ambient vibration from a 51-story high-rise building, but also the relations of the floor acceleration and velocity as a function of the wind speed and floor height of the building would be established. The structural array data recorded at the SK Tower and the measured wind data from the Taipei meteorological station (TAP), about $850 \mathrm{~m}$ apart from SK Tower are used in this paper. The SK Tower is located in Taipei. It is a tall steel building in a very active typhoon region of the world. The building has 51 stories with a total height of $244.15 \mathrm{~m}$ at 
the roof (see Figure 1). The floor plan of the SK Building, as shown in Figure 2, shows that a typical floor of the SK building is composed of a rectangular, having a length of $46.5 \mathrm{~m}$ in the NS $\mathrm{y}-\mathrm{y}$ (longitudinal) direction and a width of $34.5 \mathrm{~m}$ in the EW x-x (lateral) direction. The longitudinal direction of the building is along the true north-south axis. The building was completed in 1993.

The structural array of SK Tower uses central recording; sensors are placed at various selected locations in the building, cables are used to send analog signals from the sensors to the central signal conditioning box. Digitization and recording are then performed at the central site. The main advantage of this system is that it is based on well proven technology [11]. A total of 29 sensors are placed at the basement $7^{\text {th }}$, basement $1^{\text {th }}, 3^{\text {th }}, 18^{\text {th }}, 32^{\text {th }}$ and $47^{\text {th }}$ floor and the roof. These floors are at height of $-25.0 \mathrm{~m},-4.0 \mathrm{~m}, 10.7 \mathrm{~m}, 82.4 \mathrm{~m}, 136.2 \mathrm{~m}, 193.8 \mathrm{~m}$, and $205.3 \mathrm{~m}$ relative to the ground surface, respectively (see Figure 2). The measured wind data, including the wind speed and wind direction, were obtained at the TAP station of the Central Weather Bureau (CWB) of Taiwan, at a height of $34.9 \mathrm{~m}$ above ground. The anemometer, installed on the roof of the main CWB Building, was the R.M. Young's propeller anemometer (Model 05103 made in USA). The measurement ranges of the anemometer for wind speed and direction were from 0 to $60 \mathrm{~m} / \mathrm{s}$ and from $0^{\circ}$ to $360^{\circ}$, respectively.

\subsection{Records of the Chi-Chi Earthquake and Ambient Vibrations}

An earthquake of Mw magnitude 7.6 took place in central Taiwan on 21 September 1999, local time (20 September UTC). This was the largest inland earthquake to occur in Taiwan in the twentieth century. Its strong shakings caused devastating impacts at cities and towns as far as $150 \mathrm{~km}$ away and destroyed several

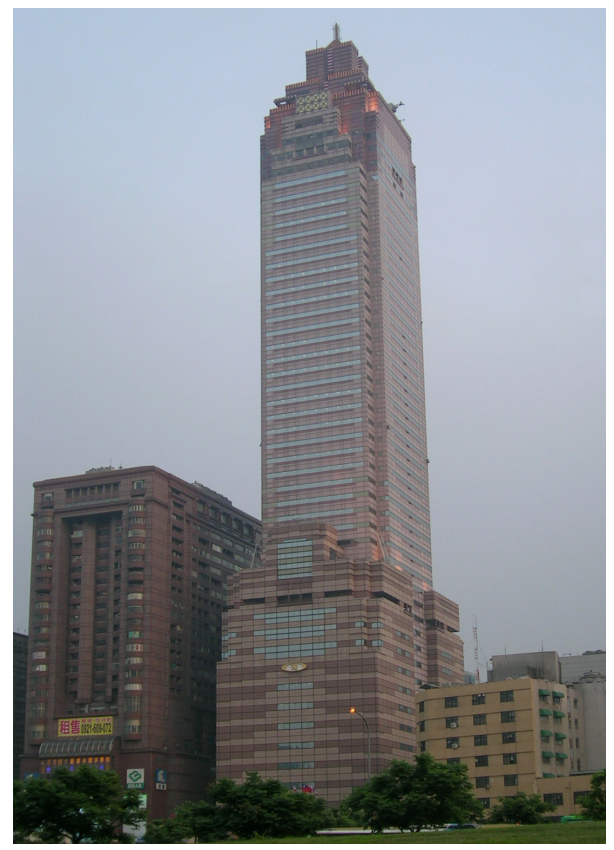

Figure 1. The SK Tower in Taipei. 


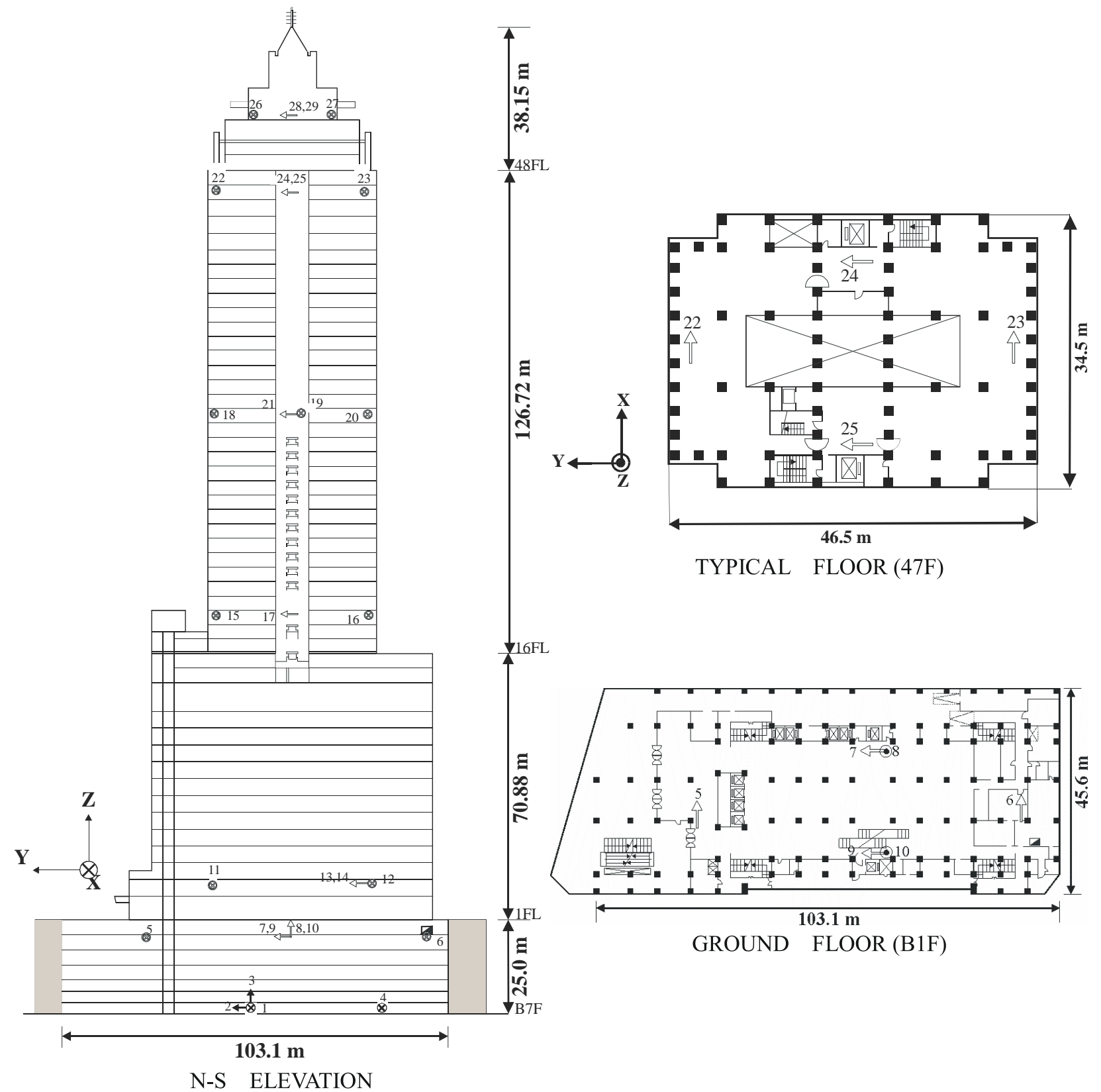

Figure 2. Configuration of the SK Tower: elevation and floor plans. The sensor locations are indicated by arrows.

high-rise buildings in Taipei Basin [12]. Records of the Chi-Chi earthquake from the structured array in the SK Tower were retrieved. The largest peak acceleration of $186.7 \mathrm{~cm} / \mathrm{sec}^{2}$ was recorded at Channel 27, located in the roof of the SK Tower. In addition, we also recorded the ambient vibrations of the SK Tower for a 45-minute duration on 6 September 2004. The data was recorded by free running the system continuously with a gain set at 10 , the record length of each segment was $62.3 \mathrm{~s}$, at a sampling rate of 200 samples per second per channel.

\subsection{Records of the Typhoon Aere}

The SK tower is also situated in one of the most active typhoon regions in the 
world. Typhoons attacking Taiwan mainly originate in the western Pacific Ocean. The tropical depression Aere was developed over the Pacific Ocean at about $2000 \mathrm{~km}$ southeast of Taipei in the morning of 20 August 2004. It intensified into a tropical storm later that afternoon. Typhoon Aere is then moved in a northwest course and attained typhoon strength on 22 August. It turned westwards on 24 August and skirted the northern coast of Taiwan the following day. Typhoon Aere caused 24 deaths and left nine people missing in Taiwan. During Typhoon Aere, the maximum 1-minute mean wind speed of $13.3 \mathrm{~m} / \mathrm{sec}$ was measured by the anemometer installed at the TAP station at local time of 22:47 (TPT), 24 August 2004. Figure 3 shows the time histories of wind speed, together with the wind direction for 48 hours. These wind data, together with the building response data are used in the data analysis.

\section{Analysis Methods}

\subsection{Relationships of the Peak Floor Acceleration and Velocity as Function of the Wind Speed and Floor Height}

A two-stage procedure is used to estimate the floor acceleration and velocity of vibrations of the tall building. A mathematical formulation, using two independent parameters that is the wind speed and floor height in the building, is further established to estimate the floor acceleration and velocity of the tall building excited

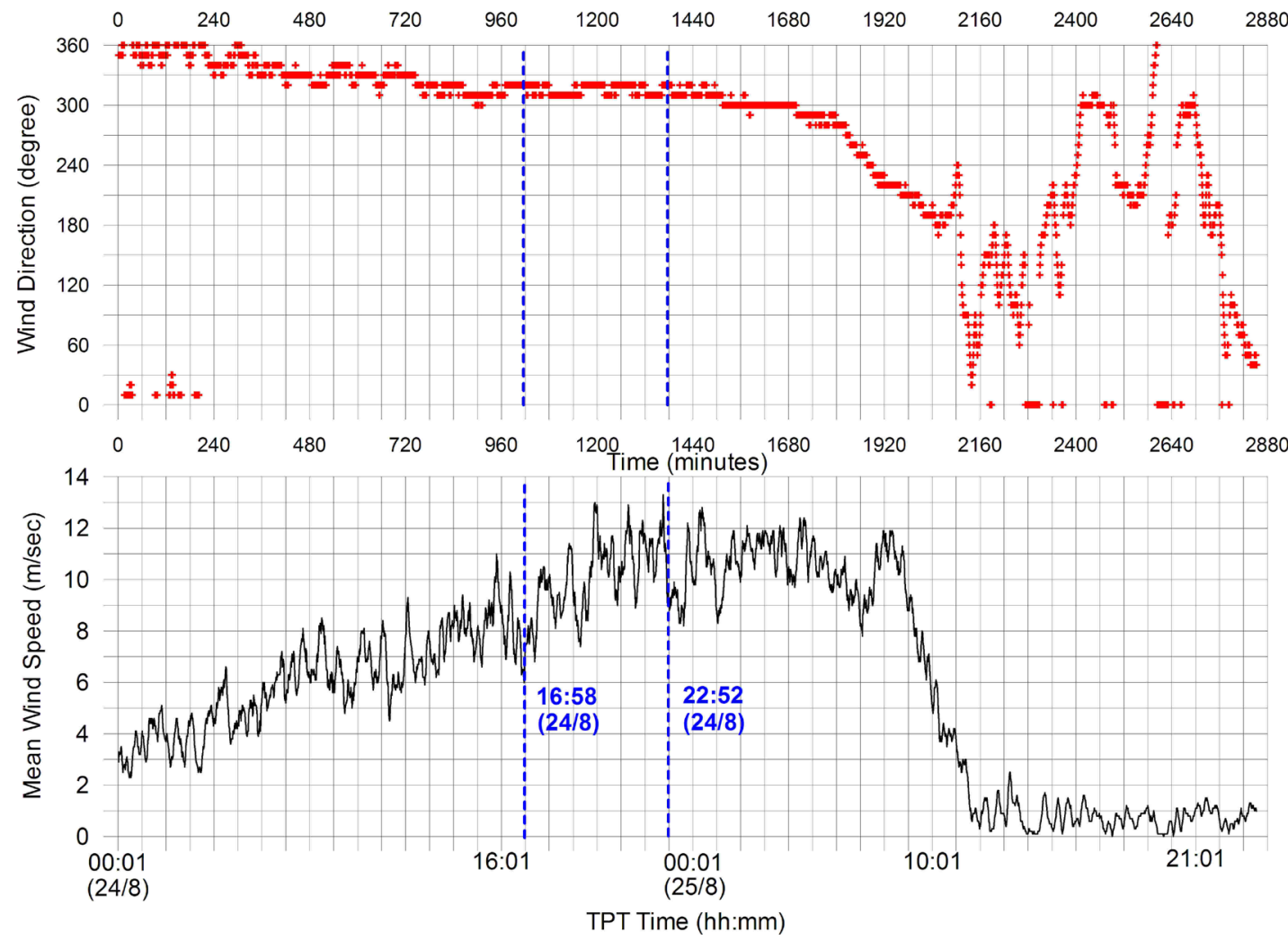

Figure 3. The one-minute mean wind speed and direction. The vertical dotted lines mark the time interval for the 354-minute duration, starting from 16:58 TPT, 24 August 2004 and ending at 22:52 TPT, 24 August 2004. The data in this interval are used in the analysis. 
by typhoon force.

The relationships express the peak floor acceleration and velocity of vibration of the tall building as a function of two simple parameters representing the wind speed and the floor height of the building. The following functional form is established in this study:

$$
\ln Y=a X+b H+c \pm \sigma
$$

where $Y$ is the peak floor acceleration (PFA) or velocity (PFV) of building vibration; $X$ is the wind speed; $H$ is the floor height of the building; $a$ is a wind speed coefficient; $b$ is a height coefficient; $c$ is a constant; $\sigma$ is the standard deviation. The coefficients $a, b$, and $c$ are determined by regression from the data. In this study, the three coefficients in the above formula for predicting building vibration are determined using a two-stage regression procedure. A similar approach was used previously to obtain the strong ground motion attenuation relationships by Joyner and Boore (1993) [13] and Liu and Tsai (2005) [14]. In the first stage the wind speed coefficient "a" was determined along with a set of amplitude factors, one for each recorded floor. In the second stage, the floor amplitude factors were regressed against floor height in the building to determine the height coefficient "b", as well as the constant "c".

\subsection{Natural Frequencies of the SK Tower}

Different sets of model parameters can be determined from the recorded time histories by several system identification methods, either in the frequency domain or time domain. Most common used methods are based on frequency domain [15]. In order to identify the natural frequencies of the SK Tower, two different methods in frequency domain, i.e. the transfer function (TF) method and the power spectral density (PSD) method, are used. The TF method applies to the earthquake records, whereas the PSD method applies to the records of the typhoon and ambient vibrations [16].

\section{Results and Discussion}

The variations of wind speed and wind direction averaged over one-minute intervals are plotted in Figure 3 for the data obtained at the TAP station. In the figure, the $\mathrm{x}$-coordinate is the Taipei local time (TPT) and the measurement data started from 00:01 TPT, 24 August 2004 and ended at 23:59 TPT, 25 August 2004. Due to limitation of hard disk capacity of the structural array, we started free running mode to record the time histories of the SK Tower response to Typhoon Aere for a 354-minute duration starting from 16:58 TPT, 24 August 2004 until 22:52 TPT, 24 August 2004.

In order to obtain the relationships of the peak floor acceleration and velocity versus the wind speed, and floor height, the 1-minute averaged wind speed values for an 354-minute duration, starting from 16:58 TPT, 24 August 2004 and ending at 22:52 TPT, 24 August 2004 are used in the analysis. It can be seen that the mean wind to the SK Tower, mainly blew from the north-northwest direc- 
tion between 16:58 TPT, 24 August and 04:00 TPT, 25 August 2004. The wind direction then changed gradually from northwest to the south in a counterclockwise until 10:00 TPT, 25 August, as Typhoon Aere passed by northern Taiwan from east to west.

\subsection{Relations between the Floor Motion versus the Wind Speed and Floor Height of the SK Building}

In this study, we examine the variation of Peak Floor Acceleration (PFA) and Peak Floor Velocity (PFV) of the SK Tower with respect to 1-min-mean wind speed and the height of individual floors. Figure 4(a) displays the smoothened PFA, half of the peak-to-peak acceleration, of the lateral (EW direction) acceleration time-history of the SK Tower, recorded by the sensor located on its south side for a 354-minute duration. It shows significant differences in the peak acceleration at different floor levels, (or height) in the building. It is interesting to note that the PFA increases with the floor height and has a positive correlation with the wind speed. Similar results are found in the corresponding PFV data, as shown in Figure 4(b).

Regressions on the data set, using the two-stage regression method described above, have resulted in the coefficients of the relationships for floor motion, as given in Table 1, for the longitudinal (NS) and lateral (EW) components of Peak Floor Acceleration (PFA), Peak Floor Velocity (PFV). In Table 1, $\sigma$ refers to the standard deviation on $\ln (Y)$. As regressions are done on a data set of the 1-minute averaged wind speed, which were measured at the TAP station at a height of $34.9 \mathrm{~m}$ above the ground level, it is different from the standard height of $10 \mathrm{~m}$ above the ground level adopted by the World Meteorological Organization. To correct the anemometer height to the standard level or other desired heights, the power law equation can be used:

$$
\frac{V(z)}{V_{\delta}}=\left(\frac{Z}{\delta}\right)^{\alpha}
$$

where $V(z)$ is the wind speed estimated at desired height $\mathrm{z}, \mathrm{V} \delta$ is the wind speed at boundary layer height $\delta$, and $\alpha$ is the power law index. The values of $\alpha$ and $\delta$ for TAP station are 0.25 and 400, respectively, which were estimated by the Taiwan Central Weather Bureau based on local topographic conditions surrounding the station [17].

Figure 5(a) plots the predicted mean values of the longitudinal (NS) and lateral (EW) peak floor acceleration of the tall building due to typhoon force as a function of mean wind speed, at a height of $34.9 \mathrm{~m}$ above the ground level. The solid lines represent the median predictions of mean wind speed ranging from 6 to $13.3 \mathrm{~m} / \mathrm{s}$ for floor height of $100 \mathrm{~m}$ and $200 \mathrm{~m}$. From the figure, we can see the predicted floor acceleration is higher in the EW component than in the NS component. This is mainly due to the greater stiffness of the building in the longitudinal direction than the lateral direction.

Figure 5(b) plots the predicted mean values of the longitudinal (NS) and lateral 


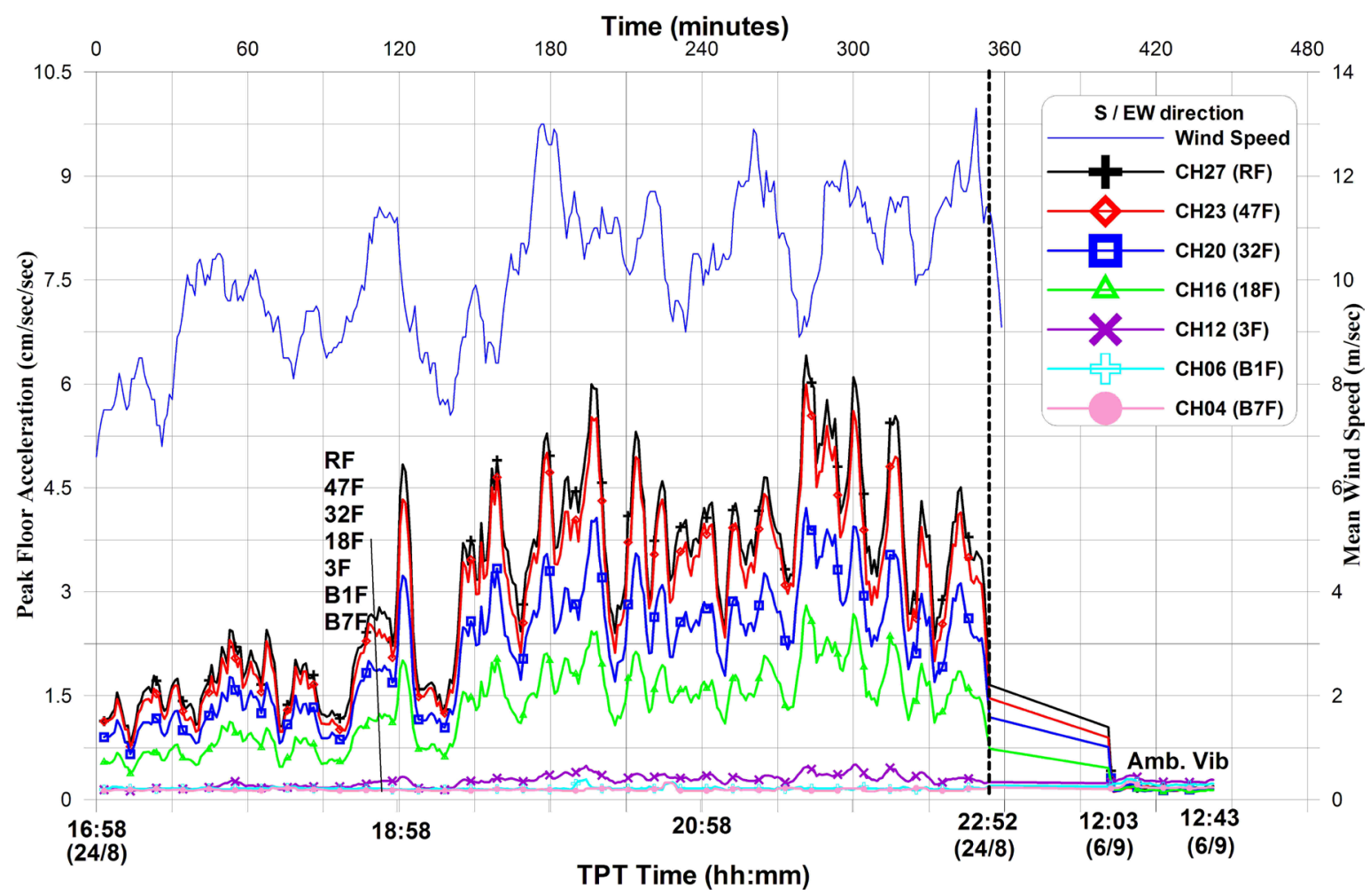

(a)

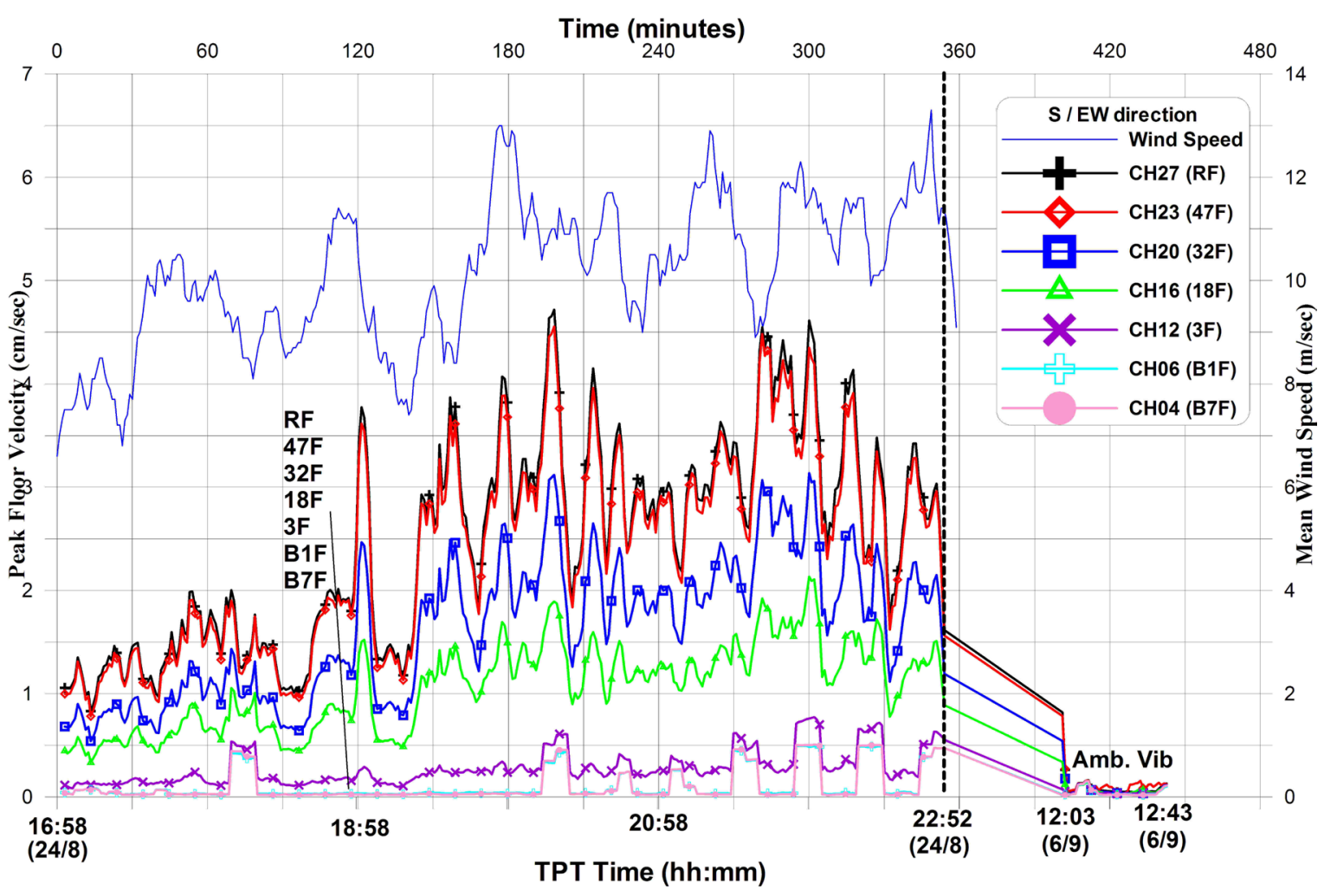

(b)

Figure 4. (a) The smoothened Peak Floor Acceleration (PFA), half of the peak-to-peak acceleration, of the lateral (EW direction) acceleration time-history of the SK Tower, recorded by the sensor located on the south side for a 354-m duration. (b) shows the corresponding Peak Floor Velocity (PFV) data. 


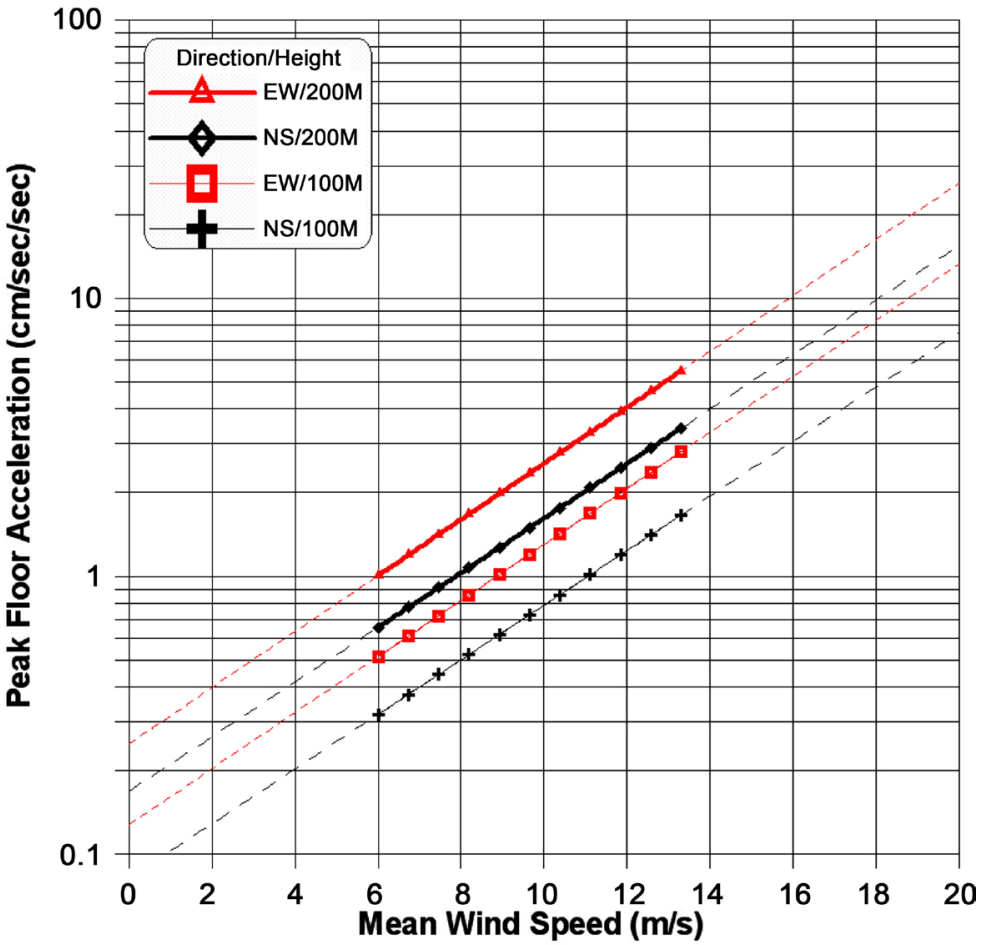

(a)

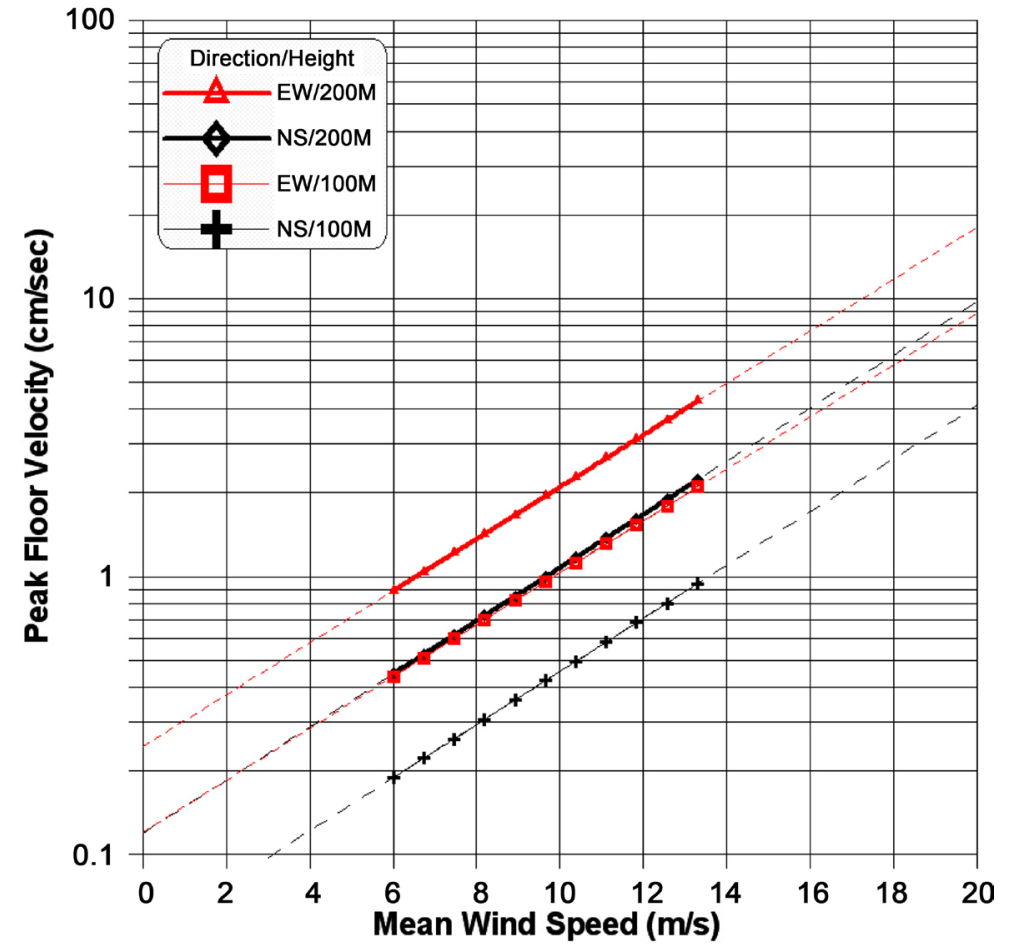

(b)

Figure 5. (a) The predicted mean values of peak floor acceleration due to typhoon force in the longitudinal (NS) and lateral (EW) direction, as a function of the mean wind speed for the SK Tower. The solid lines represent the median predictions at the mean wind speed ranging from 6 to $13.3 \mathrm{~m} / \mathrm{s}$ for the floor height of $100 \mathrm{~m}$ and $200 \mathrm{~m}$ in the building. The dashed lines represent extrapolations. (b) shows the corresponding peak floor velocity data. 
Table 1. The regression coefficients for building vibrations as function of floor height and wind speed of Typhoon Aere.

\begin{tabular}{ccccccccc}
\hline \multirow{2}{*}{$\begin{array}{c}\text { Comp. } \\
\text { Vibration Amp. }\end{array}$} & \multicolumn{3}{c}{ NS-Component } & \multicolumn{5}{c}{ EW-Component } \\
\hline PFA (gal) & 0.226 & 0.0072 & -3.219 & 0.468 & 0.232 & 0.0067 & -2.726 & 0.456 \\
PFV (cm/sec) & 0.220 & 0.0086 & -3.845 & 0.478 & 0.215 & 0.0071 & -2.828 & 0.440 \\
\hline
\end{tabular}

Remark: Building vibration model: $\ln (\mathrm{PFA}, \mathrm{PFV})=a^{*} X+b^{*} H+c \pm \sigma$, where PFA is peak floor acceleration in gal, $\mathrm{PFV}$ is peak floor velocity in $\mathrm{cm} / \mathrm{sec}, X$ is wind speed in $\mathrm{m} / \mathrm{sec}, H$ is floor height in $m$, and $\sigma$ is the standard deviation.

(EW) peak floor velocity for the tall building due to typhoon force, as a function of mean wind speed. The solid and dashed lines represent the same meanings as Figure 5(a). From Figure 5(b), we can also find higher floor velocity for the EW component than the NS component. Additionally, from Figure 5(a) and Figure 5(b) and Table 1, it is noted the regression coefficient "a" of the mean wind speed has higher values for the floor acceleration than that for the floor velocity of the building. This means that the contribution of wind force is greater to the floor acceleration than to the floor velocity of the building.

\subsection{Natural Frequencies of Vibration of the SK Tower}

In this study, the Chi-Chi earthquake record is used to determine the natural frequencies of the first three modes. Higher modes are not considered since they are of less significance in actual building responses [18]. Accordingly, the recorded data in the SK Tower are available from the Chi-Chi earthquake, typhoon Aere and ambient vibrations identify the natural frequencies of the $1^{\text {st }}, 2^{\text {nd }}$, and $3^{\text {rd }}$ modes of vibration in the longitudinal and lateral directions.

Figure 6 shows the lateral (EW) transfer functions in the frequency domain from the Chi-Chi earthquake data of north-side sensors in the SK Tower. By examining the measured transfer functions, the natural frequencies of the $1^{\text {st }}, 2^{\text {nd }}$, and $3^{\text {rd }}$ lateral modes of the SK Tower are found to be $0.205,0.500$, and $0.969 \mathrm{~Hz}$, respectively. In addition, the $1^{\text {st }}$ torsional mode is also found between $0.25 \sim 0.4$ $\mathrm{Hz}$ in the lateral component. The corresponding results of the longitudinal component are $0.247,0.590$, and $1.060 \mathrm{~Hz}$, respectively. Because the SK Tower is a steel structure, the corresponding fundamental mode period, according to the building code can be calculated as follows [19]:

$$
T=0.085 h_{n}^{3 / 4}
$$

where $h_{n}$ is the height of building from the ground. The computed natural frequency of the fundamental mode according to the building code is $0.217 \mathrm{~Hz}$. When this frequency is compared with those identified from actual data, we can find that the code formula tends to underestimate and overestimate the fundamental frequency by $5.53 \%$ and $13.82 \%$ for lateral and longitudinal component, respectively, as given in Table 2 and Table 3. It is also found from Figure 6 that: 1) the amplitudes are almost the same at the $1^{\text {st }}$ and $2^{\text {nd }}$ lateral natural frequencies 


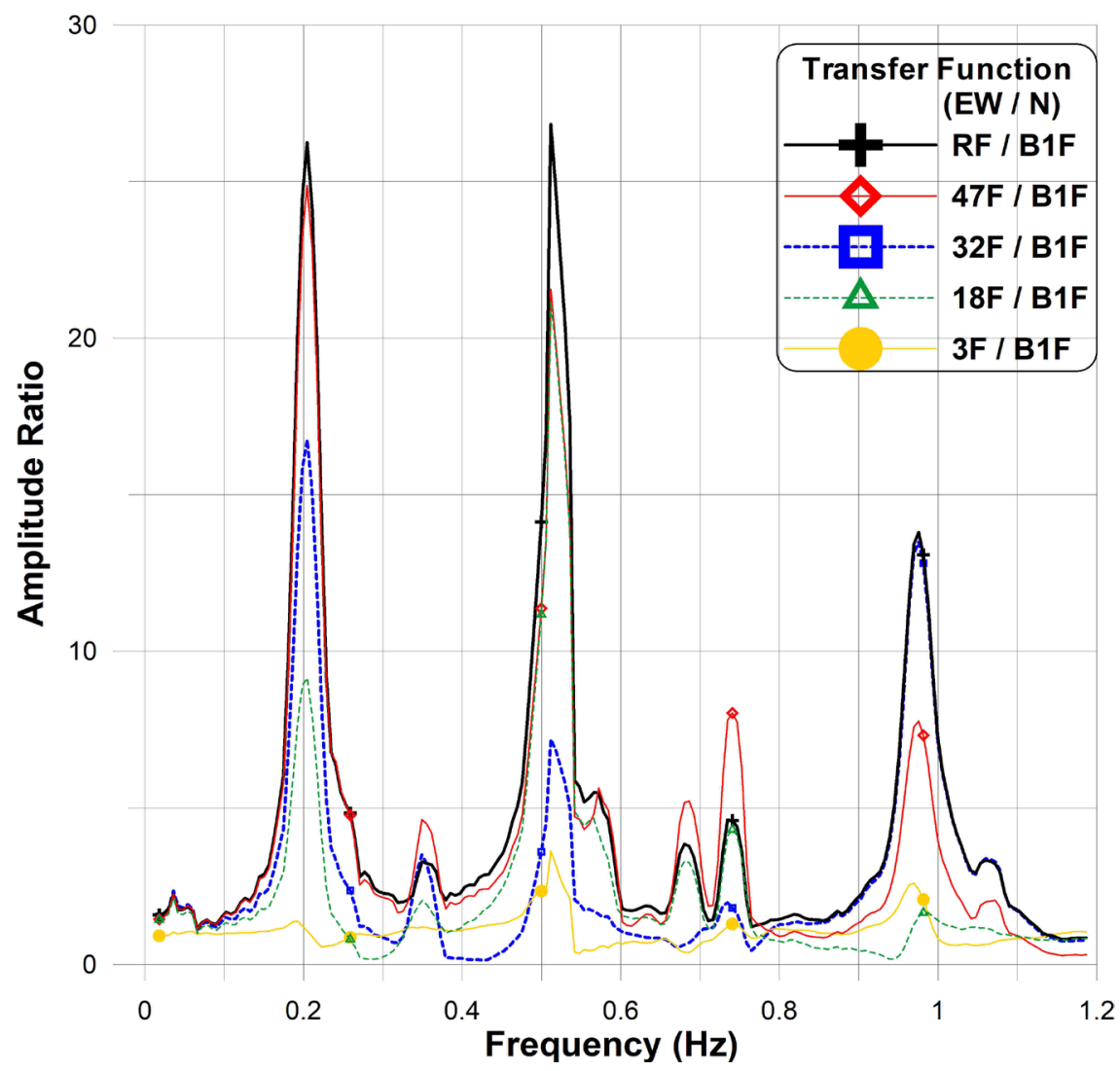

Figure 6. The transfer functions of vibration of the SK Tower in frequency domain for the lateral (EW) component.

Table 2. The observed mode frequencies $\mathrm{f}(\mathrm{Hz})$ and percentage deviation of mode frequency relative to the calculated Building Code value $\delta(\%)$ in the lateral (EW) directions of the SK Tower.

\begin{tabular}{cccccc}
\hline Mode & $\begin{array}{c}\text { Source } \\
\text { type Para. }\end{array}$ & $\begin{array}{c}(1) \\
\text { Chi-Chi Earthquake }\end{array}$ & $\begin{array}{c}(2) \\
\text { Typhoon Aere }\end{array}$ & $\begin{array}{c}(3) \\
\text { Ambient Vibrations }\end{array}$ & $\begin{array}{c}(4) \\
\text { Building Code(2001) }\end{array}$ \\
\hline $1^{\text {st }} \mathrm{EW}$ & $f_{1}$ & 0.205 & $0.210 \pm 0.006$ & $0.217 \pm 0.005$ & 0.217 \\
$2^{\text {nd }} \mathrm{EW}$ & $f_{2}$ & 0.500 & $0.519 \pm 0.012$ & $0.539 \pm 0.010$ & \\
$3^{\text {rd }} \mathrm{EW}$ & $f_{3}$ & 0.969 & $1.002 \pm 0.014$ & $1.027 \pm 0.013$ \\
$1^{\text {st }} \mathrm{EW}$ & $\delta_{1}$ & -5.53 & -3.23 & 0.00 \\
\hline
\end{tabular}

Table 3. The observed mode frequencies $\mathrm{f}(\mathrm{Hz})$ and percentage deviation of mode frequency relative to the calculated Building Code value $\delta(\%)$ in the longitudinal (NS) directions of the SK Tower.

\begin{tabular}{cccccc}
\hline Mode & $\begin{array}{c}\text { Source } \\
\text { type Para. }\end{array}$ & $\begin{array}{c}(1) \\
\text { Chi-Chi Earthquake }\end{array}$ & $\begin{array}{c}(2) \\
\text { Typhoon Aere }\end{array}$ & $\begin{array}{c}(3) \\
\text { Ambient Vibrations }\end{array}$ & $\begin{array}{c}(4) \\
\text { Building Code(2001) }\end{array}$ \\
\hline $1^{\text {st }} \mathrm{NS}$ & $f_{1}$ & 0.247 & $0.255 \pm 0.009$ & $0.267 \pm 0.009$ & 0.217 \\
$2^{\text {nd }} \mathrm{NS}$ & $f_{3}$ & 0.590 & $0.614 \pm 0.018$ & $0.644 \pm 0.009$ & \\
$3^{\text {rd }} \mathrm{NS}$ & $f_{5}$ & 1.060 & $1.117 \pm 0.017$ & $1.148 \pm 0.011$ & \\
$1^{\text {st }} \mathrm{NS}$ & $\delta_{1}$ & 13.82 & 17.51 & 23.04 & \\
\hline
\end{tabular}


of the SK Tower as well as the $3^{\text {rd }}$ one is the smallest. 2) The amplitude ratios of the roof to the basement are a multiple of 26,27 , and 14 with respect to the $1^{\text {st }}$, $2^{\text {nd }}$, and $3^{\text {rd }}$ lateral natural frequencies, respectively.

After having identified the natural frequencies of the $1^{\text {st }}, 2^{\text {nd }}$, and $3^{\text {rd }}$ modes from the Chi-Chi earthquake data, we now proceed to analyze the typhoon and ambient vibration data. These observed values and relative ratios are compared with the corresponding building code values for the $1^{\text {st }}, 2^{\text {nd }}$, and $3^{\text {rd }}$ natural frequencies in the lateral (EW) (dark line) and longitudinal (NS) (light line) directions in Table 2, Table 3 and Figure 7. The standard deviations of the typhoon and ambient vibration data are also shown in Table 2 and Table 3 . In addition, I also checked whether the length of segment used to process the data would have a significant effect on the estimates of natural frequencies. The resolution bandwidth $\Delta \mathrm{f}$ for spectral estimate is equal to $1 / T$ (or $1 / N \Delta t$ ) where $\mathrm{T}$ is the length of the data segment, $\mathrm{N}$ is the number of points in the segment, and $\Delta t$ is the time

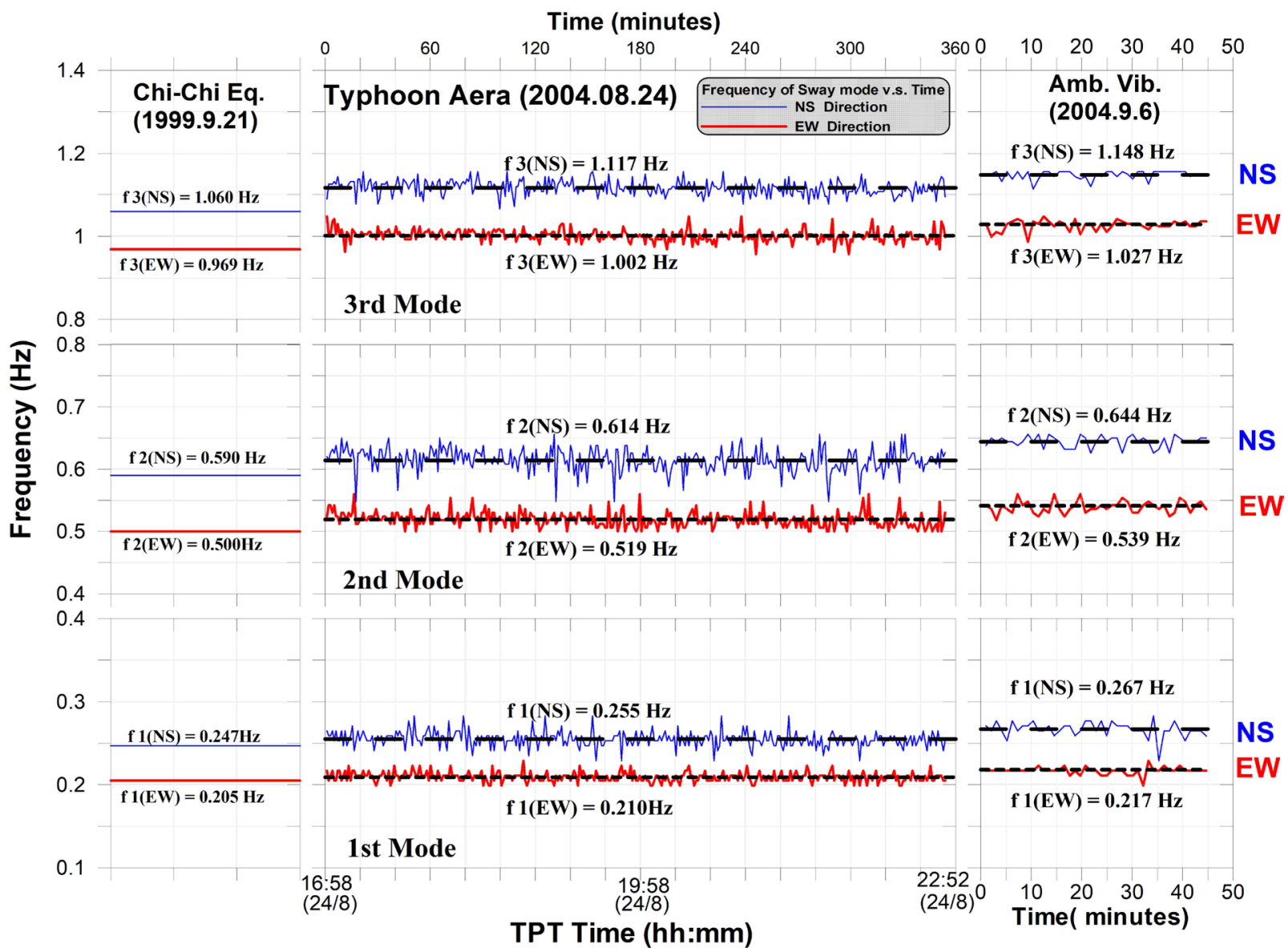

Figure 7. The natural frequencies of the $1^{\text {st }}, 2^{\text {nd }}$, and $3^{\text {rd }}$ mode in the lateral (EW) (dark line) and longitudinal (NS) (light line) directions determined from the recorded data of the earthquake, typhoon and ambient vibrations. The left and right side of Figure 7 shows the frequencies of the $1^{\text {st }}, 2^{\text {nd }}$, and $3^{\text {rd }}$ mode as obtained respectively from the recorded data of the Chi-Chi earthquake (in a straight line which is made up of 1 record) and ambient vibration data (in zigzag line which is made up of 43 segments). The middle side shows similar results from the recorded data of Typhoon Aere (in zigzag line which is made up of 341 segments). The dashed and thick dashed lines stand for the average natural frequencies, which were calculated from total segments of records, in the lateral (EW) and longitudinal (NS) directions, respectively. 
interval of sampling points [20]. In this study, $\mathrm{N}=32,768\left(2^{15}\right)$ and $\Delta t=0.005$ sec. Accordingly, $\Delta f=0.0061 \mathrm{~Hz}$. By comparing the modal frequencies obtained from the three different types of excitation, as given in Table 2 and Table 3, the present resolution bandwidth is deemed adequate.

In the left and right side of Figure 7 shows the frequencies of the $1^{\text {st }}, 2^{\text {nd }}$, and $3^{\text {rd }}$ mode as obtained respectively from the recorded data of the Chi-Chi earthquake (in a straight line which is made up of 1 record) and ambient vibration data (in zigzag line which is made up of 43 segments). In the middle part are showing similar results from the recorded data of Typhoon Aere (in zigzag line which is made up of 341 segments). The dashed and thick dashed lines stand for the average natural frequencies, which were calculated from total segments of records, in the lateral (EW) and longitudinal (NS) directions, respectively. From Figure 7, we can see: 1) the observed natural frequencies changed from low to high due to the earthquake, the typhoon and then the ambient vibrations. This means the larger external force acting on the building, the lower natural frequencies will become. 2) The natural frequencies of the lateral (EW) component are lower than that of longitudinal (NS) component. This is probably due to the greater stiffness of the building in the longitudinal direction than in the lateral direction.

\section{Conclusions}

This study uses the in-structure recordings to investigate the vibration characteristics of a 51-story steel high-rise building in response to a major earthquake, typhoon and ambient vibrations. This presents an opportunity for us to compare the building behaviors, especially their modal properties under different types of excitation. From the results presented above, we can draw the following conclusions:

1) The measured wind data and the structural array data are analyzed in this paper, using a two-stage regression procedure, to obtain the formulas for estimating the building response parameters, including the peak floor acceleration and velocity, as a function of the wind speed and floor height in the building.

2) From the formulas for building response, the predicted peak floor acceleration is higher in the lateral (EW) component than in the longitudinal (NS) component. This is probably due to the greater stiffness of the building in the longitudinal direction than in the lateral direction.

3) Moreover, we note that the regression coefficient "a" for the term of mean wind speed has higher values of the acceleration response than to the velocity response of the building. This means that the contribution of the wind force is higher to the acceleration response than to the velocity response of the building.

4) The $1^{\text {st }}, 2^{\text {nd }}$, and $3^{\text {rd }}$ lateral natural frequencies of the SK Tower after examining the observed transfer functions are found to be $0.205,0.500$, and 0.969 $\mathrm{Hz}$, respectively. The corresponding results for the longitudinal component are $0.247,0.590$, and $1.060 \mathrm{~Hz}$, respectively. Accordingly, these identified natural 
frequencies are compared with an appropriate formula specified in the building code. It is found that the code formula tends to underestimate and overestimate the fundamental frequency of the building by $5.53 \%$ and $13.82 \%$ for the lateral and longitudinal component, respectively.

5) After having identified the $1^{\text {st }}, 2^{\text {nd }}$, and $3^{\text {rd }}$ natural frequencies using the recorded data from the earthquake, typhoon and ambient vibrations, the ranking of the fundamental natural frequencies from low to high is the Chi-Chi earthquake, Typhoon Aere and the ambient vibrations.

6) The natural frequencies are higher for the longitudinal (NS) component than in the lateral (EW) component. This is probably because the stiffness of the building is greater in the longitudinal direction than in the lateral direction.

\section{Acknowledgements}

I thank the Central Weather Bureau of Taiwan for providing excellent structural array and wind data for the present study. I also appreciate greatly two anonymous reviewers for their valuable comments, which improved the article. This research was supported by the Ministry of Science and Technology (MOST) of Taiwan under Grant No. MOST106-2116-M-244-001.

\section{References}

[1] Wang, Y.H., Lee, I.H. and Wang, D.P. (2005) Typhoon Induced Extreme Coastal Surge: A Case Study at Northern Taiwan in 1994. Journal of Coastal Research, 21, 548-552. https://doi.org/10.2112/03-0026.1

[2] Volkovas, V., Uldinskas, E. and Eidukevičiūtè, M. (2012) Investigation of Dynamic and Precision Characteristics of Low Frequency Vibration Measurement Device. Journal of Vibroengineering, 14, 52-60.

[3] Celebi, M., Phan, L.T. and Marshall, R.D. (1993) Dynamic Characteristics of Five Buildings during Strong and Low-Amplitude Motions. International Journal of the Structural Design of Tall Buildings, 2, 1-15. https://doi.org/10.1002/tal.4320020102

[4] Soyoz, S., Feng, M.Q. and Shinozuka, M. (2010) Structural Reliability Estimation with Vibration-Based Identified Parameters. Journal of Engineering Mechanics, ASCE, 136, 100-106. https://doi.org/10.1061/(ASCE)EM.1943-7889.0000066

[5] Soyoz, S., Taciroglu, E., Orakcal, K., Nigbor, R., Skolnik, D., Lus, H. and Safak, E. (2013) Ambient and Forced Vibration Testing of a Reinforced Concrete Building before and after Its Seismic Retrofitting. Journal of Structural Engineering, ASCE, 139, 1741-1752. https://doi.org/10.1061/(ASCE)ST.1943-541X.0000568

[6] Li, Q.S., Yang, K., Zhang, N., Wong, C.K. and Jeary, A.P. (2002) Field Measurements of Amplitude-Dependent Damping in a 79-Storey Tall Building and Its Effects on the Structural Dynamic Responses. The Structural Design of Tall and Special Buildings, 11, 129-153. https://doi.org/10.1002/tal.195

[7] Liu, K.S. and Tsai, Y.B. (2010) Observed Natural Frequencies, Damping Ratios and Mode Shapes of Vibration of a 30-Story Building Excited by a Major Earthquake and Typhoon. Earthquake Spectra, 26, 371-397. https://doi.org/10.1193/1.3385471

[8] Wang, D., Zhou, Y. and Zhu, Y. (2012) Vibration Control Study on a Supertall Building. The Structural Design of Tall and Special Buildings, 21, 28-45.

https://doi.org/10.1002/tal.618 
[9] Amiri, M.M. and Yahyai, M. (2013) Estimation of Damping Ratio of TV Towers Based on Ambient Vibration Monitoring. The Structural Design of Tall and Special Buildings, 22, 862-875. https://doi.org/10.1002/tal.733

[10] Liu, K.S., Shin, T.C. and Tsai, Y.B. (1999) A Free Field Strong Motion Network in Taiwan: TSMIP. Terrestrial, Atmospheric and Oceanic Sciences, 10, 377-396. https://doi.org/10.3319/TAO.1999.10.2.377(T)

[11] Teng, T.L. (1992) Technical Report on Design and Implementation of a Prototype Realtime Strong-Motion Array System. Southern California Earthquake Center, University of Southern California, Los Angeles.

[12] Shin, T.C. and Teng, T.L. (2001) An Overview of the 1999 Chi-Chi, Taiwan, Earthquake. Bulletin of the Seismological Society of America, 91, 895-913. https://doi.org/10.1785/0120000738

[13] Joyner, W.B. and Boore, D.M. (1993) Method for Regression Analysis of Strong-Motion Data. Bulletin of the Seismological Society of America, 83, 469-487.

[14] Liu, K.S. and Tsai, Y.B. (2005) Attenuation Relations of Peak Ground Acceleration and Velocity for Crustal Earthquakes in Taiwan. Bulletin of the Seismological Society of America, 95, 1045-1058. https://doi.org/10.1785/0120040162

[15] Loh, C.H. and Lin, H.M. (1996) Application of Off-Line and On-Line Identification Techniques to Building Seismic Response Data. Earthquake Engineering and Structural Dynamics, 25, 269-290.

https://doi.org/10.1002/(SICI)1096-9845(199603)25:3<269::AID-EQE554>3.0.CO;2J

[16] Beck, J.L. and Jennings, P.C. (1980) Structural Identification using Linear Modals and Earthquake Records. Earthquake Engineering and Structural Dynamics, 8, 145-160. https://doi.org/10.1002/eqe.4290080205

[17] Chang, T.J., Wu, Y.T., Hsu, H.Y., Chu, C.R. and Liao, C.M. (2003) Assessment of Wind Characteristics and Wind Turbine Characteristics in Taiwan. Renewable Energy, 28, 851-871. https://doi.org/10.1016/S0960-1481(02)00184-2

[18] Li, Y. and Mau, S.T. (1992) Anatomy of the Loma Prieta Earthquake Records of Two Steel Buildings using MIMO System Identification. In: Proceedings of Conference Engineering Mechanics, American Society of Civil Engineers, New York, 689-693.

[19] Tsai, K.C., Loh, C.H., Yeh, C.H. and Su, C.M. (2001) Design Examples and the Recommended Modifications on the Tentative Seismic Force Provisions for Building Structures in Taiwan. Architecture \& Building Institute, Ministry of Interior Research Project Report, Taipei.

[20] Bendat, J.S. (1978) Statistical Errors in Measurement of Coherence Functions and Input/Output Quantities. Journal of Sound and Vibration, 59, 405-421.

https://doi.org/10.1016/S0022-460X(78)80007-8 